\title{
EDUCAÇÃO E TEORIAS DA APRENDIZAGEM: UM FOCO NA TEORIA DE VYGOTSKY
}

\author{
Lílian dos Santos Castro ${ }^{1 \#}$ \\ Rodrigo da Silva Santos ${ }^{2 \#}$ \\ Aline Helena da Silva $\mathrm{Cruz}^{3}$
}

1 - Universidade de São Paulo (Faculdade de Medicina de Ribeirão Preto) e Universidade de Franca (Departamento de Licenciatura em Química). Contato: 1iliancastro@usp.br (Castro, LS)

2 - Universidade de São Paulo (Faculdade de Medicina de Ribeirão Preto) e Universidade de Franca (Departamento de Licenciatura em Química). Contato: rdssantos@gmail.com (Santos, RS)

3 - Universidade de São Paulo (Faculdade de Medicina de Ribeirão Preto) e Secretaria da Educação do Estado de Goiás (SEDUC-GO). Contato: alinehelena@usp.br (Cruz, AHS)

\# Castro, LS \& Santos, RS, participaram igualmente de todas as etapas da elaboração do artigo e compartilham autoria.

Recebido em: 24/05/2013 - Aprovado em: 30/07/2013 - Disponibilizado em: 15/08/2013

RESUMO: Denominam-se teorias da aprendizagem, em Psicologia e em Educação, aos diversos modelos que visam explicar o processo de aprendizagem pelos indivíduos. A finalidade deste artigo é apresentar a importância das teorias de aprendizagem no cotidiano escolar como forma de promover o processo de ensinoaprendizagem. De um modo geral, uma teoria é uma interpretação sistemática de uma área de conhecimento. Pode-se dizer que o termo "teoria" é usado para significar uma maneira particular de ver as coisas, de explicar observações ou de resolver problemas. Teorias de aprendizagem são, portanto, tentativas de interpretar sistematicamente, de organizar, de fazer previsões sobre conhecimentos relativos à aprendizagem. Embora desde a Grécia antiga se hajam formulado diversas teorias sobre a aprendizagem, as de maior destaque na educação contemporânea são a de Jean Piaget e a de Lev Vygotsky. Neste trabalho será destacada a consciência no pensamento do pesquisador russo Lev Semenovitch Vygotsky (1896-1934) e algumas experiências educacionais. Palavras-chave: Teorias, aprendizagem, Educação e Vygotsky.

\section{EDUCATION AND THEORIES OF LEARNING: A FOCUS ON THE THEORY OF VYGOTSKY}

\begin{abstract}
Are called learning theories in Psychology and Education, the various models that aim to explain the process of learning by individuals. The purpose of this article is to present the importance of learning theories in school life as a way of promoting the teaching-learning process. In general, a theory is an interpretation of a systematic knowledge area. You could say that the term "theory" is used to mean a particular way of seeing things, to explain observations or solve problems. Learning theories are, therefore, attempts to interpret systematically organize, to make predictions about knowledge related to learning. Although since ancient Greece was formulated there are several theories about learning, the most prominent in contemporary education is that of Jean Piaget and Lev Vygotsky. In this work will be presented at the thought of consciousness Russian researcher Lev Vygotsky Semenovitch (1896-1934) and some educational experiences.
\end{abstract}

Keywords: Theories, Learning, Education and Vygotsky. 


\section{1 - INTRODUÇÃO}

O aprendizado de um indivíduo não é um fenômeno fixo e imutável, mas um processo que se inicia desde o seu nascimento, e porque não dizer deste a sua formação no ventre materno?

O fato é que estamos cercados por elementos relacionados com a educação, educação esta que tem sido diferenciada em formal, quando esta ocorre em instituições de ensino, com uma educação intencional, e informal, quando a esta ocorre ao "acaso", resultante, por exemplo, de relações interpessoais ou atos de observação.

Mas, como dito por Ramos, em seu texto introdução a teorias de aprendizagem, "para que uma pessoa atinja um determinado grau de conhecimento (instrução) é possível lançar mão de ações intencionais (ensino), segundo um processo social mais amplo (Educação)".

Sendo que, durante o processo de ensino-aprendizagem que ocorre no ambiente escolar, existem os elementos centrais para que o desenvolvimento escolar/aprendizado ocorra com sucesso: o aluno, o professor e a situação de aprendizagem.

\footnotetext{
Nesse sentido, as teorias de aprendizagem buscam reconhecer a dinâmica envolvida nos atos de ensinar e aprender, partindo do reconhecimento da
}

evolução cognitiva do homem, e tentam explicar a relação entre o conhecimento pré-existente e o novo conhecimento. A aprendizagem não seria apenas inteligência e construção de conhecimento, mas, basicamente, identificação pessoal e relação através da interação entre as pessoas (Staub, 2004).

As teorias de aprendizagem surgiram possivelmente porque, conforme salienta Bigge (1977, p.3), “o homem não só quis aprender como também, frequentemente, sua curiosidade o impeliu a tentar aprender como se aprende". Estas teorias são diversas e acompanharam de perto a evolução observada na Psicologia e na Educação. Assim, ao longo deste artigo diversas teorias de ensino-aprendizagem serão retratadas, reportando sempre que possível ao processo de ensinoaprendizagem. Com discussão baseada no pressuposto de que a qualidade do ensino em sala de aula está intimamente relacionada ao conhecimento de referenciais teóricos que orientem o planejamento, a implementação e a avaliação de práticas educacionais. 


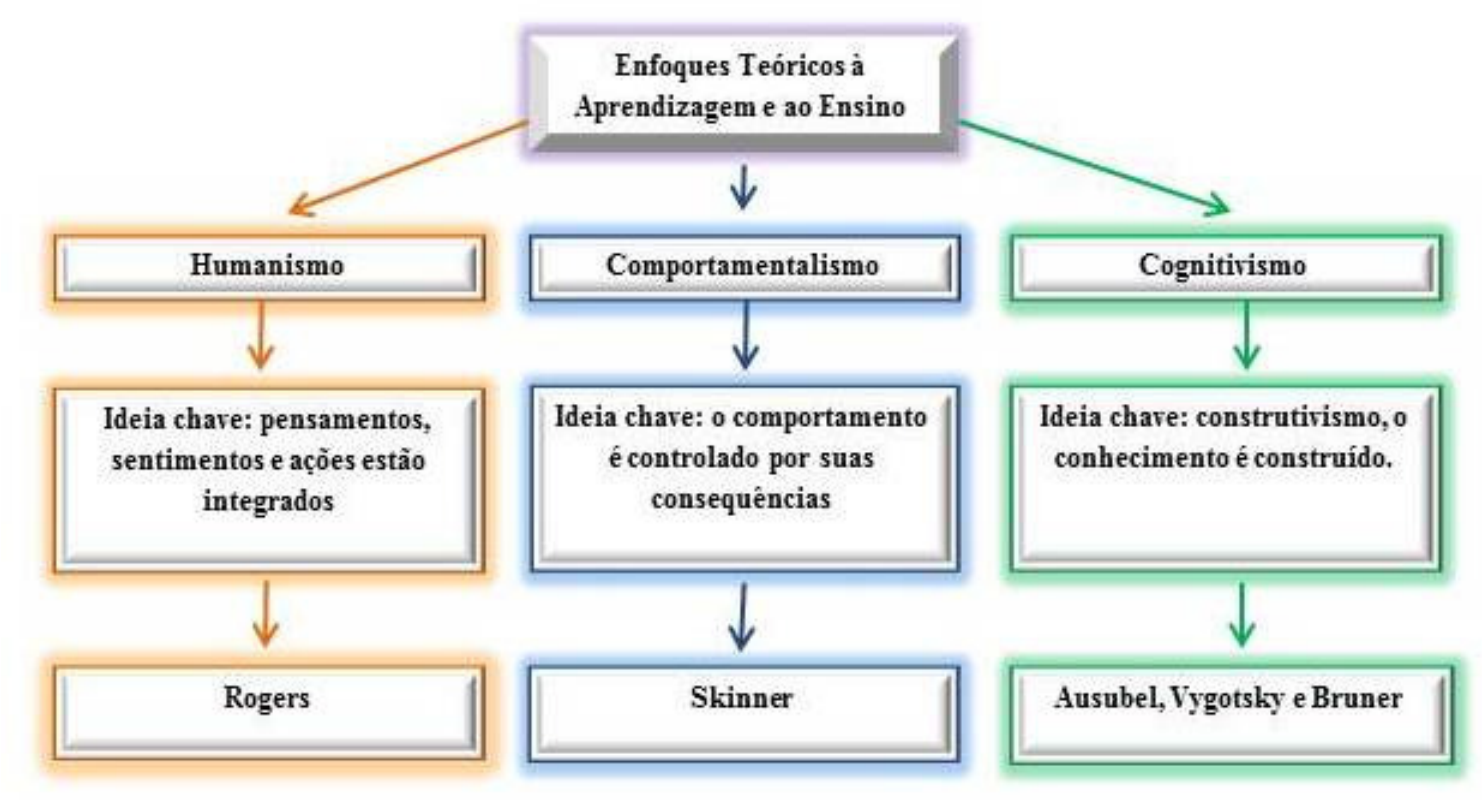

Figura 01: Exemplos de alguns teóricos da aprendizagem com suas teorias e implicações para o ensino e a aprendizagem. (Adaptado de Guedes, 2009).

\section{2 - TEORIAS DA APRENDIZAGEM}

\section{1- Humanismo}

Carl R. Rogers (1902-1987), pioneiro no desenvolvimento da chamada Psicologia Humanista, ou Terceira Força em Psicologia, segue o que é chamado de abordagem humanista, muito diferenciada dos outros teóricos, pois seu objetivo não é o controle do comportamento, o desenvolvimento cognitivo ou a formulação de um bom currículo e sim o crescimento pessoal do aluno.

Esta abordagem considera o aluno como pessoa e o ensino deve facilitar a sua auto-realização, visando à aprendizagem "pela pessoa inteira", que transcende e engloba as aprendizagens afetiva, cognitiva e psicomotora.

Para Rogers, só uma mudança muito grande na direção básica da educação, pode atender às necessidades da cultura de hoje. O ponto final de nosso sistema educacional, de acordo com Rogers, deve ser o desenvolvimento de pessoas "plenamente atuantes". O objetivo educacional deve ser a facilitação da aprendizagem e para que o professor seja um facilitador, segundo Rogers, ele precisa ser uma pessoa verdadeira, autêntica, genuína, despojando-se do tradicional "papel", "máscara", ou "fachada" de ser "o professor" e tornar-se uma pessoa real com seus alunos (Guedes, 2009). 


\section{2- Comportamentalismo}

Segundo Moreira (2009), Burrhus

Frederic Skinner (1904-1990) foi o teórico behaviorista que mais influenciou o entendimento do processo ensinoaprendizagem e a prática escolar. No Brasil, a influência da pedagogia tecnicista remonta à segunda metade dos anos 50, mas foi introduzida mais efetivamente no final dos anos 60, com o objetivo de inserir a escola nos modelos de racionalização do sistema de produção capitalista.

$\mathrm{O}$ objetivo do behaviorismo skinneriano é o estudo científico do comportamento: descobrir as leis naturais que regem as reações do organismo que aprende, a fim de aumentar o controle das variáveis que o afetam. Os componentes da aprendizagem - motivação, retenção, transferência - decorrem da aplicação do comportamento operante (Moreira, 2009).

Segundo Skinner, o comportamento aprendido é uma resposta a estímulos externos, controlados por meio de reforços que ocorrem com a resposta ou após a mesma: "se a ocorrência de um comportamento operante é seguida pela apresentação de um estímulo (reforçador), a probabilidade de reforçamento é aumentada" (Moreira, 2009).

\section{3- Cognitivismo}

A corrente cognitivista enfatiza o processo de cognição, através do qual a pessoa atribui significados à realidade em que se encontra. Preocupa-se com o processo de compreensão, transformação, armazenamento e uso da informação envolvido na cognição e procura regularidades nesse processo mental. Nesta corrente, situam-se autores como Jerome Seymour Bruner, Jean Piaget, David Ausubel, Gary Novak e George Alexander Kelly. Alguns deles são construtivistas com ênfase na cognição (Brunner, Piaget, Ausubel e Novak), ou enfatizam o afetivo (como Kelly e Rogers) (Bruner, 1986).

Bruner parte da hipótese de que "é possível ensinar qualquer assunto, de uma maneira honesta, a qualquer criança em qualquer estágio de desenvolvimento". Levando-se em conta o desenvolvimento intelectual da criança, a tarefa de ensinar determinada matéria é a de representar a estrutura deste conteúdo em termos da visualização que a criança tem das coisas. Segundo Bruner, o que é relevante em uma matéria de ensino é sua estrutura, suas ideias e relações fundamentais (Bruner, 1986)

De acordo com Neves (2006, p.5), o conceito central da teoria de Vygotsky é o de atividade, que é a unidade de construção da arquitetura funcional da consciência; um 
sistema de transformação do meio (externo e interno da consciência) com ajuda de instrumentos (orientados externamente; devem necessariamente levar a mudanças nos objetos) e signos (orientados internamente; dirigidos para o controle do próprio indivíduo).

Uma atividade entendida como mediação onde o emprego de instrumentos e signos representa a unidade essencial de construção da consciência humana, entendida como contato social, consigo mesmo e, por isso, constituída de uma estrutura semiótica (estrutura de signos) com origem na cultura. Para Vygotsky, o desenvolvimento humano está definido pela interiorização dos instrumentos e signos; pela conversão dos sistemas de regulação externa em meios de auto-regulação (Neves, 2006).

\subsection{1- Cognitivismo: Vygotsky}

São muitos os estudos sobre a aprendizagem e, especialmente, sobre a classificação das diferentes concepções de aprendizagem em diversas teorias, também denominadas correntes epistemológicas da psicologia da educação. Entretanto, ao longo desse estudo, podemos perceber como educadores que os autores estão longe de um consenso sobre a localização da Teoria Sócio-Histórica de Vygotsky - já aceita por muitos como uma teoria da aprendizagem - nessas classificações, mesmo contrapondo todas as ideias vigentes à época. Sendo assim, discorremos sobre a teoria e o pensamento daquele que acreditamos ser 0 marco para 0 entendimento dessa relação entre psicologia e processos educativos: Lev Semenovitch Vygotsky. Para Vygotsky, a aprendizagem não era uma mera aquisição de informações, não acontecia a partir de uma simples associação de ideias armazenadas na memória, mas era um processo interno, ativo e interpessoal (Vygotsky, 1989).

Vygotsky concebe o homem como um ser histórico e produto de um conjunto de relações sociais. Ele se pergunta como os fatores sociais podem modelar a mente e construir o psiquismo e a resposta que apresenta nasce de uma perspectiva semiológica, na qual o signo, como um produto social, tem uma função geradora e organizadora dos processos psicológicos (Vygotsky, 1989).

O ser humano é visto como alguém que transforma e é transformado nas relações que acontecem em uma determinada cultura. O que ocorre não é uma somatória entre fatores inatos e adquiridos e sim uma interação dialética que se dá, desde o nascimento, entre o ser humano e o meio social e cultural em que se insere. Assim, é possível constatar que o ponto de vista de Vygotsky é que: 
o desenvolvimento humano é compreendido não como a decorrência de fatores isolados que amadurecem, nem tampouco de fatores ambientais que agem sobre o organismo controlando seu comportamento, mas sim como produto de trocas recíprocas, que se estabelecem durante toda a vida, entre indivíduo e meio, cada aspecto influindo sobre o outro. (Freitas, 2000).

Vygotsky não nega que exista diferença entre os indivíduos, que uns estejam mais predispostos a algumas atividades do que outros, em razão do fator físico ou genético. Contudo, não entende que essa diferença seja determinante para a aprendizagem. Além disso, ele rejeita os modelos baseados em pressupostos inatistas que determinam características comportamentais universais do ser humano, como, por exemplo, expressam as definições de comportamento por faixa etária, por entender que o homem é um sujeito datado, atrelado às determinações de sua estrutura biológica e de sua conjuntura histórica (Freitas, 2000).

Discorda também da visão ambientalista, pois, para ele, o indivíduo não é resultado de um determinismo cultural, ou seja, não é um receptáculo vazio, um ser passivo, que só reage frente às pressões do meio, e sim um sujeito que realiza uma atividade organizadora na sua interação com o mundo, capaz, inclusive, de renovar a própria cultura. Portanto, para este importante pensador, nós somos sujeitos ativos, primeiro somos sociais e depois nos individualizamos (Vygotsky, 1989).

\section{3 - A REALIDADE EDUCACIONAL}

Os conflitos que a sociedade enfrenta, econômica, social, cultural e familiar, advindas das transformações sociais, refletem na escola, que por sua vez tenta solucionar os problemas que se instalam dentro da comunidade escolar.

Podemos afirmar que a escola, em seu papel mediador, pode enriquecer o indivíduo e levá-lo à luta pela transformação das relações sociais por meio da apropriação das objetivações genéricas para si, embora possa não dar conta da superação total da alienação produzida pelo sistema.

Essa preocupação com a alienação da sociedade e atuação da escola e do professor como mediador também tem sido foco de trabalho de professores envolvidos com a arte. Pois como destacado por Cruz e Cruz (2011) "no âmbito da educação formal das escolas a dança é recheada de preconceitos, tradicionalismos excludentes e, quase sempre, existe para suprir apresentações nos momentos festivos".

O grande desafio tem sido mostrar aos alunos que eles são indivíduos ativos e não marionetes.

Por meio das aulas objetiva-se o
crescimento em nível cognitivo, sócio-
afetivo e psicomotor dos alunos. (...) Os 
alunos precisam conhecer novas possibilidades do ato de movimentar-se e novos significados da arte e do belo, entendendo que não é errado gostar ou dançar os movimentos pré-moldados pela mídia, porém é preciso enxergá-los com um novo olhar, com novas perspectivas, entendendo a história da dança (Cruz e Cruz, 2011).

Pois assim como afirmado por Vygotsky, a divisão de classe prepara, desperta e provoca o desenvolvimento de certas capacidades nos indivíduos de acordo com o lugar que ocupará na sociedade. $\mathrm{O}$ grande desafio é conduzir todos os participantes da escola na busca de um ideal comum, ou seja, a socialização dos conhecimentos produzidos pela humanidade (Vygotsky, 1989; Lessa e Facci, 2009 ).

O ser humano é resultado de sua história e de relações com outras pessoas, com a família, com os grupos sociais, com a cultura elaborada no decorrer da história, com as condições sócio-econômicas que produzem determinada forma de ser. Por isso, nós como profissionais da Educação, com base em uma visão sócio-educativa, precisamos estar atentos, porque temos o privilégio de estarmos inseridos em um dos processos mais vitais e fundamentais da humanização do homem: o movimento em que ele pode apropriar-se do conhecimento e fazer dele um instrumento de desenvolvimento de suas potencialidades (Lessa e Facci, 2009).
É importante considerar que os fundamentos teóricos elaborados por Vygotsky nem sempre são observados de fato no cotidiano escolar, mas auxiliam a reflexão do processo educativo como um todo. Por outro lado também é importante considerar o olhar que Vygotsky faz na educação do sujeito, pois, observa-se que a presença marcante do pensamento marxista, se revela na sua teoria, no sentido de apresentar a relação homem-natureza, como enfoque principal do processo de desenvolvimento humano. De fato, o olhar sócio-cultural na Educação como um todo, revela o quanto o homem é submetido aos valores de sua cultura no contexto educacional (Ribeiro e Mendes, 2001; Becker, 2003).

Ribeiro e Mendes em 2001 descreveram que quando observamos na educação infantil, percebemos que os valores culturais da criança são fortemente marcados na educação que recebem, e nesse sentido os professores que atuam na educação infantil seguem a risca a determinações impostas pela direção da escola, oferecendo em sala de aula uma prática pedagógica que é elaborada pelas instâncias superiores.

Pensa-se que as professoras ao desenvolverem sua prática educativa em sala de aula assumem todas as determinações que a direção elabora, pois os livros didáticos, os exercícios 
reproduzidos e outras atividades são determinativos e não são acompanhadas por uma análise a respeito do estágio de desenvolvimento em que a criança se encontra, demonstrando que os educadores desconhecem a teoria de Vygotsky a respeito das diferentes maneiras de apropriação do conhecimento pelo aluno, o que chamamos de zona de desenvolvimento real (Ribeiro e Mendes, 2001).

\section{4 - CONCLUSÃO}

Percebe-se que mesmo, a maioria das escolas apresentando um olhar e discurso cognitivista e propostas educacionais baseadas segundo as teorias cognitivistas e vygotskyanas, nota-se que é extremamente necessário 0 desenvolvimento de um programa de aperfeiçoamento docente, uma vez que grande parte dos professores contratados não consegue identificar os fundamentos básicos pertinentes para cada teoria. Os docentes devem proporcionar ao seu aluno, a oportunidade de desenvolver-se de maneira autônoma e simultaneamente deve compreender que a teoria do pensador Vygotsky se encontra presente na prática educativa para ser além de praticada, questionada, discutida, analisada, criticada e aprofundada. Devemos ter como meta, que através da prática pedagógica podemos enriquecer essa teoria, através da contribuição do conhecimento humano, pois uma vez bloqueando o fluxo de ideias, daremos um fim para inúmeras descobertas que se esgotariam em um universo de distintas experiências.

\section{REFERÊNCIAS BIBLIOGRÁFICAS}

Becker, F. Vygotsky versus Piaget - ou sociointeracionismo e educação. In: R. L. L. Barbosa (org.), Formação de Educadores. Desafios e Perspectivas. São Paulo, Editora UNESP, n.7:69-81, 2003.

Bigge, M.L. Teorias da aprendizagem para professores. São Paulo: Editora Pedagógica e Universitária, 1977.

Bruner, J.S. Actual minds, possible words. Cambridge, MA: Harvard University Press, 1986.

Cruz, E.I.S. e Cruz, A. H.S. "É gostando que se aprende" - ensino da dança na escola: uma experiência pedagógica que tem funcionado. Livro de Atas, Seminário Internacional, Faculdade de Motricidade Humana, 10-13 nov. 2011.

Freitas, M.T. A. As apropriações do pensamento de Vygotsky no Brasil: um tema em debate. In: Psicologia da Educação. Revista do Programa de Estudos Pós-Graduados em Psicologia da Educação. Pontifícia Universidade Católica de São Paulo, n.10/11: 9-28, 2000.

Guedes, S.S. Teorias da Aprendizagem. Técnicas Instrumentais de Didática Contemporânea - TIDC. 2009.

Lessa, PV; Facci, MGD. O psicólogo escolar e seu trabalho frente ao fracasso escolar numa perspectiva crítica. ABRAPEE - Congresso Nacional de 
Psicologia Escolar e Educacional (ISSN 1981-2566). 2009.

Moreira, M.A. Teorias de Aprendizagem. São Paulo: Editora Pedagógica e Universitária, 1999.

Neves, S.R. de A., Damiani, M.F. Vygotsky e as teorias da aprendizagem. UNIrevista Vol. 1, n²: Abril, 2006.

Ramos, E. M. F. Introdução a Teorias de Aprendizagem. Curso de Capacitação em Educação à Distância, UNESP. Disponível em:

http://www.rc.unesp.br/pef/estante/Aprendi zagem_modelos.pdf . Acesso em: 19 de maio de 2013.

Ribeiro, C. e Mendes, PR. Contribuições de Piaget e Vygotsky para a formação do professor (a) da educação infantil de 0 a 6 anos. Trabalho de Conclusão de Curso. Universidade da Amazônia (UNAMA). 2001.

Staub, A.L.P. Teorias da Aprendizagem. Trabalho de conclusão da disciplina de Prática Educativa em Medicina (AE Dom Bosco). 2004.

Vygotski, L.S. Pensamento e linguagem. São Paulo: Martins Fontes, 1989. 